\title{
Randomised Phase 2 study of maintenance linsitinib (OSI-906) in combination with erlotinib compared with placebo plus erlotinib after platinum-based chemotherapy in patients with advanced non-small cell lung
} cancer

Tudor-Eliade Ciuleanu*,1, Samreen Ahmed ${ }^{2}$, Joo-Hang Kim³ ${ }^{3}$, Jörg Mezger ${ }^{4}$, Keunchil Park ${ }^{5}$, Michael Thomas ${ }^{6}$, Jihong Chen ${ }^{7,9}$, Srinivasu Poondru7, Jan M VanTornout ${ }^{7,9}$, Debbie Whitcomb ${ }^{7}$ and Fiona Blackhall ${ }^{8}$

${ }^{1}$ Oncological Institute I Chiricuta and UMF Iuliu Hatieganu, Cluj-Napoca, Romania; ${ }^{2}$ Leicester Royal Infirmary, Leicester, UK; ${ }^{3} \mathrm{CHA}$ Bundang Medical Center, CHA University, Gyeonggi-do, Korea; ${ }^{4}$ Saint Vincentius-Kliniken Karlsruhe, Karlsruhe, Germany; ${ }^{5}$ Samsung Medical Center Sungkyunkwan University School of Medicine, Seoul, Korea; ${ }^{6}$ Translational Lung Research Center Heidelberg (TLRC-H), Member of the German Center for Lung Research (DZL), Heidelberg, Germany; ${ }^{7}$ Astellas Pharma Global Development, Northbrook, IL, USA and ${ }^{8}$ Manchester University and The Christie Hospital NHS Foundation Trust, Manchester, UK

Background: Maintenance therapy is important in advanced/metastatic non-small cell lung cancer (NSCLC). Erlotinib as switch maintenance following platinum-based chemotherapy increases survival. Cross-talk between the epidermal growth factor receptor and insulin-like growth factor receptor (IGFR) pathways mediate resistance to individual receptor blockade. This study compared maintenance linsitinib plus erlotinib vs erlotinib plus placebo in patients with NSCLC.

Methods: In this Phase II randomised trial, patients without progression following four cycles of first-line platinum-based chemotherapy $(N=205)$ received continuous schedule maintenance oral linsitinib $150 \mathrm{mg}$ or placebo BID combined with erlotinib $150 \mathrm{mg}$ QD for 21-day cycles. The primary endpoint was progression-free survival (PFS).

Results: The study was unblinded early due to linsitinib non-superiority. No difference was found between the two treatment groups in median PFS of 125 days linsitinib vs 129 days placebo ( $P=0.601)$; no difference in overall survival (OS) was observed. Tolerability was similar, although in the linsitinib group, treatment-related adverse events and discontinuations were more frequent. No drug-drug interaction was implicated.

Conclusions: Linsitinib maintenance therapy added to erlotinib did not improve PFS or OS in non-progressing NSCLC patients. This highlights the need for robust biomarkers of response for combinations that incorporate IGFR-targeted therapies in maintenance or other therapeutic settings.

*Correspondence: Dr T-E Ciuleanu; E-mail: Tudor_ciuleanu@hotmail.com

${ }^{9}$ Formerly with Astellas Pharma Global Development at the time of this study.

Received 31 May 2016; revised 20 June 2017; accepted 22 June 2017; published online 3 August 2017

(C) 2017 Cancer Research UK. All rights reserved 0007-0920/17 
An estimated 1.8 million new cases and 1.6 million deaths in 2012 were attributed to lung cancer, the most common cancer worldwide (Torre et al, 2015). Non-small cell lung cancer (NSCLC) accounts for approximately $85-90 \%$ of lung cancer cases, most of which are advanced or metastatic with poor prognosis and limited treatment options. Although treatment options for NSCLC have been advanced by the introduction of molecularly targeted agents that inhibit activating driver variants in genes such as ALK, EGFR, and ROS1 (Paez et al, 2004; Rosell et al, 2009; Rothschild, 2015), standard-of-care first-line therapy in patients who do not harbour targetable mutations typically consists of 4-6 cycles of platinum doublet therapy (Manegold, 2014).

Following progression on first-line therapy, options are limited, with only about $50-60 \%$ of patients able to receive second-line therapy because of declining performance status (Manegold, 2014). Therefore, an important option to prolong the clinical benefit obtained by first-line platinum-containing chemotherapy is the use of maintenance therapy until disease progression or unacceptable toxicity. Maintenance therapy can either be continuation maintenance of first-line therapy or a switch to a different agent after four cycles of platinum therapy (switch maintenance approach) (Genestreti et al, 2015; Zhang et al, 2015). Agents used in continuation maintenance chemotherapy include pemetrexed (Paz-Ares et al, 2013), bevacizumab (Sandler and Herbst, 2006), and, arguably, gemcitabine (Perol et al, 2012), or a combination of bevacizumab and gemcitabine (Patel et al, 2013). Switch maintenance agents include chemotherapeutic agents such as pemetrexed (Ciuleanu et al, 2009), as well as targeted agents such as erlotinib (Cappuzzo et al, 2010; Perol et al, 2012) and gefitinib (Zhang et al, 2012). Maintenance therapy has yielded improvements in overall survival (OS) and progression-free survival (PFS) in some studies. Specifically, switch therapy to a new type of agent (either epidermal growth factor receptor-tyrosine kinase inhibitors (EGFR-TKIs) or chemotherapy) may decrease chemotherapy resistance (Genestreti et al, 2015). However, the extent of improvement varies with the type of maintenance therapy and the patient population (Lu et al, 2015; Zhang et al, 2015; Zhou et al, 2015).

Erlotinib, an EGFR-TKI used for first-line therapy in patients with NSCLC with sensitising mutations (Melosky, 2014), has demonstrated statistically significant, although modest, increases in PFS (3.0 vs 2.8 months) and OS (12.0 vs 11.0 months) compared with placebo when used as switch maintenance after four cycles of platinum-based chemotherapy in a randomised, Phase III clinical trial (Cappuzzo et al, 2010). However, in most patients, erlotinib resistance is an eventual occurrence, either from primary resistance or as acquired resistance via secondary EGFR mutations (e.g., T790M mutation in exon 20) or alterations in alternative pathways (e.g., MET, human epidermal growth factor 2 (HER2), $B R A F$ ) (Stewart et al, 2015; Chung, 2016).

The insulin-like growth factor 1 (IGF-1) signalling pathway is involved in tumour cell proliferation, survival, and invasiveness, and shares downstream signalling pathways (such as MAPK and PI3K) with EGFR (Fidler et al, 2012; Stewart et al, 2015). Studies have shown that increased activity of insulin-like growth factor 1 receptor (IGF-1R) leads to tumourigenesis. IGF-1R is aberrantly expressed in tumours, and its overexpression is associated with decreased survival in several tumour types, including NSCLC (Pollack, 2012; Kim et al, 2014; King et al, 2014). Furthermore, acquired resistance to reversible EGFR-TKIs has been reported in NSCLC cells engaging this pathway, whereas an IGF1-R inhibitor combined with erlotinib suppressed the emergence of TKI resistance (Sharma et al, 2010).

As such, IGF-1R has developed into an important target for NSCLC treatment, particularly in combination with EGFR inhibitors such as erlotinib (Fidler et al, 2012). Objective response to monotherapy with IGF-1R monoclonal antibodies is rare, possibly due to expression of an aberrant form of the insulin receptor (IR), which may confer resistance to anticancer therapy and compensate for IGF-1R inhibition (Beliafore et al, 2009; Ulanet et al, 2010). Therefore, enhanced anti-tumour activity may be achieved by co-inhibition of IGF-1R and IR (Buck et al, 2010; Janssen and Varewijck, 2014). Furthermore, when combined with an EGFR-TKI, this co-inhibition may reduce the development of resistance due to the bidirectional cross-talk between the two receptors and the EGFR pathway (Fidler et al, 2012; Gao et al, 2012).

Linsitinib, an orally bioavailable, dual IGF-1R and IR inhibitor, has preclinical anti-proliferative effects in tumour cell lines and anti-tumour activity in IGF-1R xenograft models, including lung cancer (Ji et al, 2007; Mulvihill et al, 2009; McKinley et al, 2011; Zinn et al, 2013). Preliminary anti-tumour efficacy results were observed for single-agent linsitinib in patients with solid tumours, including partial responses in patients with melanoma and adrenocortical carcinoma (Fassnacht et al, 2015; Jones et al, 2015; Puzanov et al, 2015). Furthermore, preclinical studies have shown linsitinib enhancement of erlotinib activity (Zhao et al, 2012), suggesting that linsitinib would be a promising agent for combination with EGFR inhibitors, especially in patients with NSCLC in whom cross-talk between the IGF-1R and EGFR pathways has been well established (Fidler et al, 2012; Pillai and Ramalingam, 2013). A Phase I study of linsitinib and erlotinib combination, which included patients with NSCLC, illustrated a tolerable safety profile with no pharmacokinetic (PK) interaction between linsitinib and erlotinib (Macaulay et al, 2016).

We report the results of a Phase II study designed to compare the effect of maintenance linsitinib plus erlotinib, $v s$ erlotinib monotherapy, on PFS in patients with NSCLC with nonprogression following four cycles of first-line platinum-based chemotherapy. Secondary efficacy endpoints included disease control rate (DCR), response upgrade rate (RUR), overall response rate (ORR), duration of response, and OS. Additionally, the safety profile and the PK of the linsitinib/erlotinib maintenance combination were evaluated.

\section{MATERIALS AND METHODS}

Eligibility. Patients with histologically confirmed advanced NSCLC stages IIIB or IV with complete response (CR), partial response $(\mathrm{PR})$, or stable disease $(\mathrm{SD})$ following completion of firstline platinum-based chemotherapy were eligible. Patients with disease progression at the time of study entry were not eligible. Testing for EGFR mutation status by either local or central testing was also required for study participation. Patients had an Eastern Cooperative Oncology Group performance status 0-1, a fasting glucose $\leqslant 150 \mathrm{mg} / \mathrm{dL}$, and adequate haematopoietic, hepatic, and renal function. Patients with diabetes mellitus requiring insulinotropic or insulin therapy, a history of poorly controlled gastrointestinal disorders, or significant cardiovascular disease were excluded. Patients who had received prior IGF-1R therapy or concurrent maintenance bevacizumab were excluded.

The study was conducted in accordance with the International Conference on Harmonization Good Clinical Practice with the ethical principles of Helsinki and approved by the independent ethics committee or institutional review board for each site. Patients provided written consent prior to study initiation. The study is registered with ClinicalTrials.gov, NCT01186861.

Study design. Patients who met study criteria were randomised $1: 1$ to receive maintenance oral linsitinib $150 \mathrm{mg}$ (recommended Phase II single-agent dose (Puzanov et al, 2015)) or placebo BID on a continuous schedule combined with erlotinib $150 \mathrm{mg}$ QD (approved single-agent dose), both starting on Day 1 and 
continuing for the entire treatment period (TP; 21 days). Patients were stratified by EGFR-activating mutation type (wild-type vs exon 19 deletion/exon 21 L858R point mutation; non-activating mutations were grouped with wild-type), tumour histology (squamous $v s$ non-squamous), response to prior platinum-based chemotherapy (CR/PR vs SD), and smoking history (never vs former $v s$ current). Dose modifications of either study drug could be made at the discretion of the investigator and were guided by the toxicity deemed most causally related to study treatment. Safety and efficacy data were reviewed by the data monitoring committee (DMC) at periodic intervals. Following recommendation of the DMC on 23 April 2013, all patients were unblinded because of lack of efficacy and discontinued from linsitinib or placebo. Patients remained on erlotinib and were followed for safety.

Efficacy and safety analysis. The primary efficacy endpoint, PFS, was defined as the time from randomisation to disease progression based on Response Evaluation Criteria in Solid Tumors (RECIST) v1.1 (Eisenhauer et al, 2009). Secondary efficacy endpoints included OS, defined as the time from randomisation to documented death; ORR, defined as the proportion of patients with best overall response of CR or PR according to RECIST 1.1; DCR, defined as the proportion of patients with best overall response of $\mathrm{CR}, \mathrm{PR}$, or $\mathrm{SD}$ (with minimum duration of 6 weeks); RUR, defined as the proportion of patients with a response upgrade in comparison to their best response at the start of the study. Additional secondary objectives included PFS according to EGFR mutation status and to squamous/non-squamous histology. Exploratory endpoints included expression of genes and proteins related to epithelial-to-mesenchymal transition (a potential biomarker of response to linsitinib) such as E-cadherin protein expression, as well as Kirsten rat sarcoma viral oncogene (KRAS) and phosphatidylinositol-4,5-bisphosphate 3-kinase and catalytic subunit alpha (PIK3CA) mutation status, and their relationship to clinical outcomes.

Blood and tissue samples were collected to assess PK, pharmacodynamic, and exploratory biomarkers. The PK analysis set included treated patients who had at least one blood sample with known time of sampling and dosing on the day of sampling. Plasma samples were used to measure concentrations of linsitinib and erlotinib. Pharmacodynamic and exploratory biomarker analyses consisted of the evaluation of proteins and nucleic acids in tumour samples or protein expression from tumour samples. KRAS and PIK3CA mutations were evaluated from plasma or tumour sample DNA. Tissue samples were also analysed to determine E-cadherin protein expression (e.g., above median, below median, and highest or lowest quartile) by means of immunohistochemistry (Quintiles, Westmont, IL, USA). Plasma concentrations of IGF-1 were measured and compared predose in TPs 1 to 5 .

The safety population included all patients who received at least one dose of treatment, and evaluation was based on adverse events (AEs), serious AEs (SAEs), clinical laboratory tests (haematology and biochemistry), physical examination, vital signs, and electrocardiogram data. Adverse events and laboratory findings were graded according to the National Cancer Institute Common Terminology Criteria for Adverse Events v4.02.

Statistical analysis. Kaplan-Meier method was used to analyse the primary endpoint of PFS by treatment group. Hazard ratio (HR) of the treatment effect along with 95\% confidence interval (CI) was calculated using a Cox proportional hazard model. The study was powered based on the secondary efficacy variable, OS. The sample size of $N=200$ (130 events) would yield $82 \%$ power to detect a $67 \%$ improvement, alpha $=0.05$. The study was to continue followup 5 months after the PFS primary analysis, which was powered ( $>99 \%, n=171$ PFS events) to detect a $109 \%$ improvement in the linsitinib group compared with the placebo group using a two-sided log-rank test at a significance level of 0.05 . The actual number of PFS events was 149 , due to mandatory unblinding of the study prior to the pre-specified primary analysis of PFS. Patients who had not progressed at the time of analysis were censored at the date of last tumour assessment when non-progression was documented. PFS was also analysed using log-rank stratified by EGFR mutation status and histology. OS was analysed using the same statistical method as PFS, and patients still alive at the time of analysis were censored at the last alive date.

Response rates (DCR, RUR, and ORR) were analysed using Fisher's exact test. PK analyses were summarised using descriptive statistics, as were demographic and other baseline characteristics. Analyses were performed using Statistical Analysis Software v9.1.

\section{RESULTS}

Patients. The study was conducted at 80 sites in nine countries including Brazil (15), Canada (7), Germany (13), Poland (6), Romania (7), Russia (8), South Korea (8), the United Kingdom (7), and the United States (9). Efficacy, disposition, and safety analyses were based on a July 2013 data cut-off. A total of 205 patients were randomised, 102 to the linsitinib/erlotinib group and 103 to the placebo/erlotinib group; all were included in the final analysis set.

The safety analysis set comprised 201 patients who received at least one dose of study drug (100 in the linsitinib/erlotinib group and 101 in the placebo/erlotinib group). All 201 treated patients had at least one blood sample collected for PK analyses and made up the PK analysis set. After the start of treatment, 88 patients (86.3\%) receiving linsitinib/erlotinib discontinued treatment compared with $81(78.6 \%)$ receiving placebo/erlotinib. Most patients (74.6\%) discontinued because of disease progression $(71.6 \%$ linsitinib/erlotinib and $77.8 \%$ placebo/erlotinib). A similar proportion of patients in each group reported AEs as the primary reason for discontinuation (11.4\% linsitinib/erlotinib and $8.6 \%$ placebo/ erlotinib). Other reasons for discontinuation included withdrawal of consent and medical/ethical reasons (6.8 and 1.1\% linsitinib/ erlotinib and 2.5 and $3.7 \%$ placebo/erlotinib, respectively).

The median duration of exposure to active comparison treatment was similar in the two treatment groups. In the linsitinib/erlotinib group, patients had a median duration of 104.5 days on linsitinib and 105 days on erlotinib. In the placebo/ erlotinib group, the median duration was 105 days for both placebo and erlotinib. Baseline patient characteristics were balanced between the two groups (Table 1). The median age was 61 years (range 36-83), and the majority of patients were male (62.4\%) and white $(75.6 \%)$. The median time from initial diagnosis to randomisation was 4.6 months, and most patients had stage IV disease (92.2\%) and adenocarcinoma histology (67.3\%). A larger proportion of patients in the placebo group received prior radiation (22.3\% placebo vs $15.7 \%$ linsitinib), and best response prior to locally advanced or metastatic treatment was fairly even in the two treatment groups with $\mathrm{PR}=24.8$ vs $29.1 \%$ and $\mathrm{SD}=71.6$ vs $68.9 \%$ in the linsitinib/erlotinib group vs placebo/erlotinib group, respectively.

Efficacy. Data monitoring committee reviewed the safety and efficacy data at predefined enrolment and event intervals throughout the study. Following a DMC analysis that showed no difference in superiority between the linsitinib/erlotinib and placebo/erlotinib groups, the study was terminated and unblinded prior to the pre-specified PFS analysis. No statistically significant difference was found between the two treatment groups in PFS. Median PFS (linsitinib/erlotinib vs placebo/erlotinib) was 125 vs 129 days $(P=0.601)$ (Table 2, Figure $1 \mathrm{~A})$. Additionally, subgroup analyses of the full analysis set (patients with at least one dose of linsitinib) showed no PFS differences between the two treatment 
Table 1. Baseline patient characteristics

\begin{tabular}{|c|c|c|c|}
\hline & Linsitinib/erlotinib $(n=102)$ & Placebo/erlotinib $(n=103)$ & Total $(N=205)$ \\
\hline Age, median (range) & $62.0(36-81)$ & $60.0(40-83)$ & $61.0(36-83)$ \\
\hline $\begin{array}{l}\text { Sex, } n(\%) \\
\text { Male } \\
\text { Female }\end{array}$ & $\begin{array}{l}62(60.8) \\
40(39.2)\end{array}$ & $\begin{array}{l}66(64.1) \\
37(35.9)\end{array}$ & $\begin{array}{r}128(62.4) \\
77(37.6)\end{array}$ \\
\hline $\begin{array}{l}\text { Race, } n(\%)^{a} \\
\text { White } \\
\text { Black } \\
\text { Asian } \\
\text { Other }\end{array}$ & $\begin{aligned} 78 & (76.5) \\
4 & (3.9) \\
17 & (16.7) \\
3 & (2.9)\end{aligned}$ & $\begin{aligned} 77 & (74.8) \\
1 & (1.0) \\
24 & (23.3) \\
1 & (1.0)\end{aligned}$ & $\begin{aligned} 155 & (75.6) \\
5 & (2.4) \\
41 & (20.0) \\
4 & (2.0)\end{aligned}$ \\
\hline $\begin{array}{l}\text { ECOG performance status score, } n(\%) \\
0 \\
1\end{array}$ & $\begin{array}{l}36(35.3) \\
66(64.7)\end{array}$ & $\begin{array}{l}32 \text { (31.1) } \\
71(68.9)\end{array}$ & $\begin{array}{r}68(33.2) \\
137(66.8)\end{array}$ \\
\hline $\begin{array}{l}\text { Cigarette smoking history, } n \text { (\%) } \\
\text { Former smoker } \\
\text { Never smoked } \\
\text { Current smoker }\end{array}$ & $\begin{array}{l}59(57.8) \\
20(19.6) \\
23(22.5)\end{array}$ & $\begin{array}{l}60(58.3) \\
20(19.4) \\
23(22.3)\end{array}$ & $\begin{array}{r}119(58.0) \\
40(19.5) \\
46(22.4)\end{array}$ \\
\hline $\begin{array}{l}\text { NSCLC stage, } n(\%) \\
\text { Stage IIIB } \\
\text { Stage IV }\end{array}$ & $\begin{array}{c}7(6.9) \\
95(93.1)\end{array}$ & $\begin{array}{c}9(8.7) \\
94(91.3)\end{array}$ & $\begin{array}{c}16(7.8) \\
189(92.2)\end{array}$ \\
\hline $\begin{array}{l}\text { Histological subtype, } n \text { (\%) } \\
\text { Adenocarcinoma } \\
\text { Squamous cell carcinoma } \\
\text { Undifferentiated large cell carcinoma } \\
\text { Mixed histology } \\
\text { Other }\end{array}$ & $\begin{aligned} 69 & (67.6) \\
20 & (19.6) \\
2 & (2.0) \\
7 & (6.9) \\
4 & (3.9)\end{aligned}$ & $\begin{aligned} 69 & (67.0) \\
24 & (23.3) \\
1 & (1.0) \\
6 & (5.8) \\
3 & (2.9)\end{aligned}$ & $\begin{aligned} 138 & (67.3) \\
44 & (21.5) \\
3 & (1.5) \\
13 & (6.3) \\
7 & (3.4)\end{aligned}$ \\
\hline $\begin{array}{l}\text { Time from initial diagnosis, months } \\
\text { Mean (s.d.) } \\
\text { Median (range) }\end{array}$ & $\begin{array}{l}7.2(12.33) \\
4.7(4-117)\end{array}$ & $\begin{array}{l}6.7(8.48) \\
4.5(3-67)\end{array}$ & $\begin{array}{l}6.9(10.55) \\
4.6(3-117)\end{array}$ \\
\hline Prior radiation therapy, $n(\%)$ & $16(15.7)$ & $23(22.3)$ & $39(19.0)$ \\
\hline Prior disease-related surgery, $n(\%)$ & $30(29.4)$ & $33(32.0)$ & $63(30.7)$ \\
\hline $\begin{array}{l}\text { Prior regimen treatment, } n(\%) \\
\text { Neoadjuvant } \\
\text { Adjuvant }\end{array}$ & $\begin{array}{c}102(100) \\
0(0) \\
0(0)\end{array}$ & $\begin{aligned} 103 & (100) \\
0 & (0) \\
1 & (1.0)\end{aligned}$ & $\begin{aligned} 205 & (100) \\
0 & (0) \\
1 & (0.5)\end{aligned}$ \\
\hline
\end{tabular}

\section{Table 2. Summary of efficacy}

\begin{tabular}{|c|c|c|c|c|}
\hline Efficacy endpoint & Linsitinib/erlotinib $(n=102)$ & Placebo/erlotinib $(n=103)$ & $\operatorname{HR}(95 \% \mathrm{Cl})$ & $P$-value \\
\hline $\begin{array}{l}\text { Progression-free survival } \\
\text { Number of events, } n(\%) \\
\text { Median, days }(95 \% \mathrm{Cl})\end{array}$ & $\begin{array}{c}74(72.5) \\
125(88-167)\end{array}$ & $\begin{array}{l}75(72.8) \\
129(88-158)\end{array}$ & $\begin{array}{c}1.09 \\
(0.788-1.507)\end{array}$ & 0.601 \\
\hline $\begin{array}{l}\text { Overall survival } \\
\text { Number of events, } n(\%) \\
\text { Median, days }(95 \% \mathrm{Cl})\end{array}$ & $\begin{array}{c}44(43.1) \\
381(316-672)\end{array}$ & $\begin{array}{c}38 \text { (36.9) } \\
421 \text { (367-NR) }\end{array}$ & $\begin{array}{c}1.20 \\
(0.777,1.853)\end{array}$ & 0.409 \\
\hline $\begin{array}{l}\text { Best overall response, } n(\%) \\
\text { Complete response } \\
\text { Partial response } \\
\text { Stable disease } \\
\text { Progressive disease } \\
\text { Not evaluated }\end{array}$ & $\begin{array}{c}1(1.0) \\
15(14.7) \\
53(52.0) \\
27(26.5) \\
6(5.9)\end{array}$ & $\begin{array}{c}0(0) \\
12(11.7) \\
58(56.3) \\
26(25.2) \\
7(6.8)\end{array}$ & NA & NA \\
\hline $\begin{array}{l}\text { Disease control rate, }{ }^{a} \mathrm{n}(\%) \\
\quad 95 \% \mathrm{Cl}\end{array}$ & $\begin{array}{l}69(67.7) \\
(57.66-76.58)\end{array}$ & $\begin{array}{l}70(68.0) \\
(58.04-76.82)\end{array}$ & NA & NA \\
\hline $\begin{array}{l}\text { Objective response rate, }{ }^{\mathbf{b}} \mathrm{n}(\%) \\
95 \% \mathrm{Cl}\end{array}$ & $\begin{array}{l}16(15.7) \\
(9.24-24.22)\end{array}$ & $\begin{array}{l}12(11.7) \\
(6.17-19.47)\end{array}$ & NA & NA \\
\hline $\begin{array}{l}\text { Response upgrade rate, }{ }^{c} n(\%) \\
95 \% \mathrm{Cl}\end{array}$ & $\begin{array}{l}11(10.78) \\
(5.51-18.48)\end{array}$ & $\begin{array}{c}9(8.74) \\
(4.07-5.94)\end{array}$ & NA & NA \\
\hline \multicolumn{5}{|c|}{$\begin{array}{l}\text { Abbreviations: } \mathrm{Cl}=\text { confidence interval; } \mathrm{HR}=\text { hazard ratio; } \mathrm{NA}=\text { not applicable. } \\
{ }^{\mathrm{a}} \text { Disease control rate }=\text { complete response }+ \text { partial response }+ \text { stable disease. } \\
{ }^{b} \text { Overall response rate }=\text { complete response }+ \text { partial response. }\end{array}$} \\
\hline
\end{tabular}

groups based on mutation status, gender, age, histology, response to prior chemotherapy, or smoking history, of which the treatment arms were well balanced (Table 3). Furthermore, there was no difference between the two treatment groups in the secondary OS analyses (Table 2, Figure 1B). The objective response rate was $15.7 \%$ for the linsitinib group $v s 11.7 \%$ for the placebo group. 

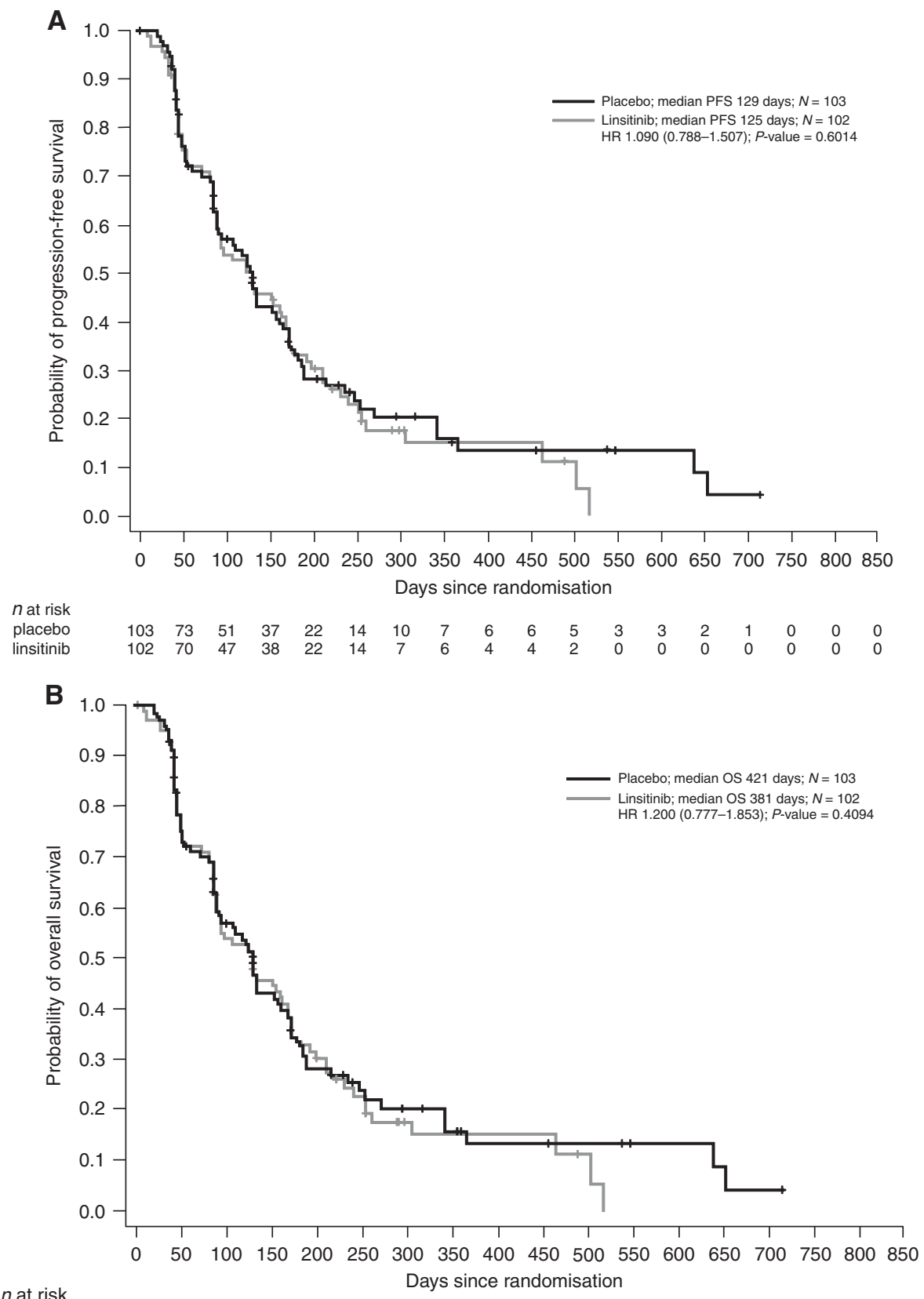

$\begin{array}{lllllllllllllllllll}n \text { at risk } & & & & & & & & & & & \\ \text { placebo } & 103 & 73 & 51 & 37 & 22 & 14 & 10 & 7 & 6 & 6 & 5 & 3 & 3 & 2 & 1 & 0 & 0 & 0 \\ \text { linsitinib } & 102 & 70 & 47 & 38 & 22 & 14 & 7 & 6 & 4 & 4 & 2 & 0 & 0 & 0 & 0 & 0 & 0 & 0\end{array}$

Figure 1. Progression-free survival (A) and overall survival (B), full analysis set. $\mathrm{Cl}=$ confidence interval; $\mathrm{HR}=$ hazard ratio.

In the linsitinib/erlotinib arm, one patient achieved CR and 15 achieved PR, whereas in placebo/erlotinib group, 12 patients achieved PR and none achieved CR (Table 2).

Median linsitinib plasma concentrations at predose and $4 \mathrm{~h}$ in all TPs are listed in Table 4. Predose concentrations of erlotinib at steady state (TP2 and TP3) were similar in both treatment groups (linsitinib/erlotinib and placebo/erlotinib) suggesting a lack of drug-drug interaction between linsitinib and erlotinib.

An increase in plasma IGF-1 concentration is an indirect measure of IGF-1R signalling inhibition. The median plasma concentrations of IGF-1 remained similar from TP1 to TP3 in patients treated with placebo/erlotinib (Table 4). In patients treated with linsitinib/erlotinib, the median predose plasma IGF-1 concentrations increased from $40 \mathrm{ng} \mathrm{ml}^{-1}$ in TP1 to $65 \mathrm{ng} \mathrm{ml}^{-1}$ in TP4, suggesting a pharmacodynamic effect.
With respect to analysis of tissue biomarkers that may have influenced efficacy, 90 patients treated with linsitinib/erlotinib and 92 patients treated with placebo/erlotinib had biomarker data (Table 3). Activating KRAS mutations were observed in 16 patients in each treatment group. Activating PIK3CA mutations were observed in one patient treated with linsitinib/erlotinib and four patients treated with placebo/erlotinib. Activating EGFR mutations were observed in 22 patients treated with linsitinib/erlotinib and 19 patients treated with placebo/erlotinib. The small number of patients with KRAS, PIK3CA, and/or EGFR mutations precluded a detailed analysis of these parameters with respect to the relationship of mutation status to patient's outcomes. E-cadherin levels were measured in 78 patients. E-cadherin $\mathrm{H}$-scores were within the normal range for the majority of patients, and were low $(<100)$ in three patients receiving linsitinib/erlotinib and six patients 
Table 3. Subgroup analysis and biomarker subgroup analysis of PFS

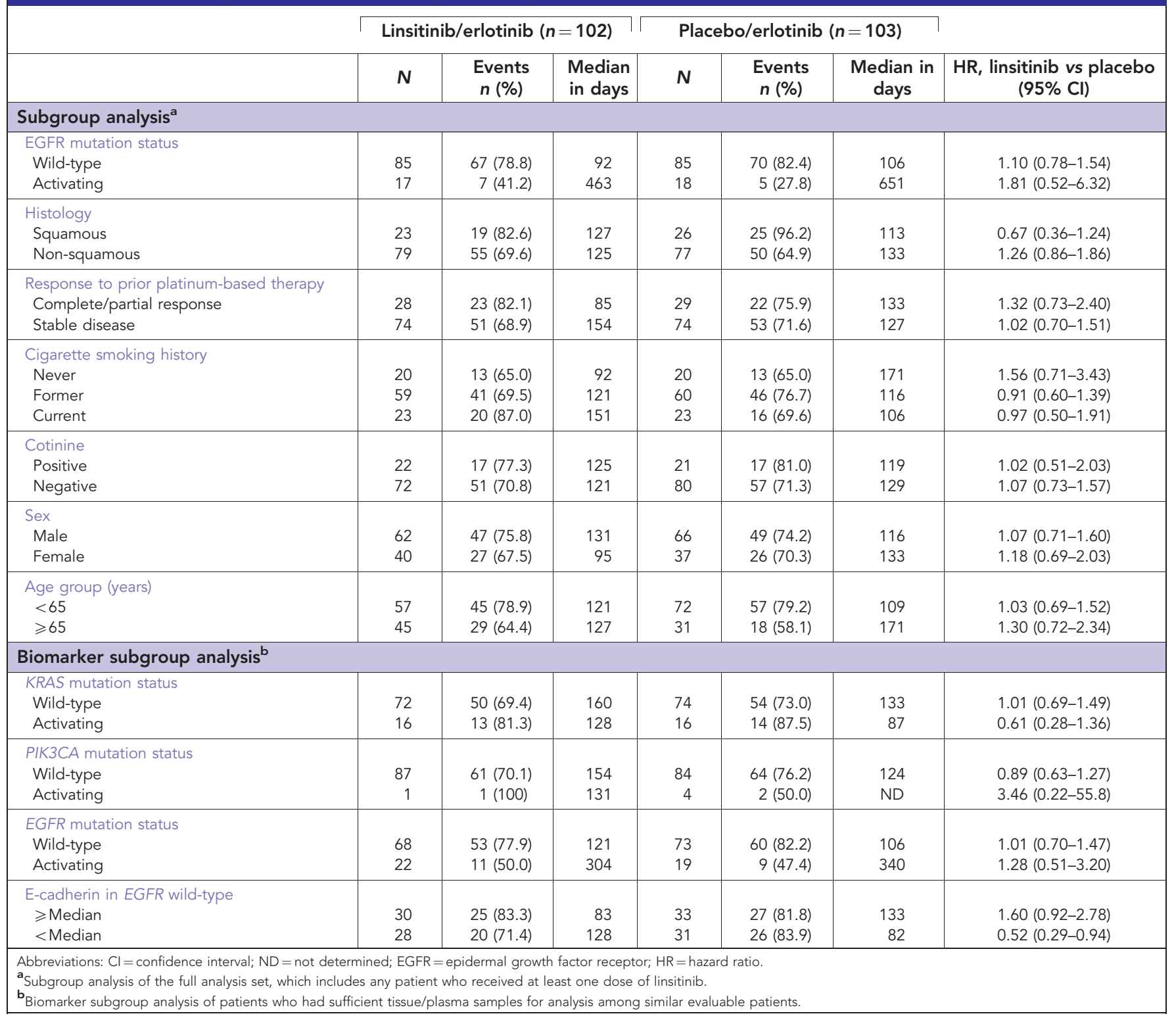

receiving placebo/erlotinib. The only significant difference in PFS was noted for a small subgroup of patients with both EGFR wildtype and E-cadherin lower than the median, favouring the linsitinib group with median PFS linsitinib/erlotinib $(n=28)$ vs placebo/erlotinib $(n=31)$ of 128 vs 82 days and HR 0.52 (0.29-0.94) (Table 3).

Safety. Treatment-emergent AEs (TEAEs) were similar in both treatment groups. The most common TEAEs (occurring in $\geqslant 20 \%$ of patients in either group) for linsitinib/erlotinib $v s$ placebo/ erlotinib were rash/drug eruption (67.0 vs 58.4\%), diarrhoea (44.0 vs $32.7 \%)$, decreased appetite (30.0 vs $20.8 \%$ ), and nausea (22.0 vs $18.8 \%)$. Grade $3 / 4$ TEAEs of rash/drug eruption (8.0\%) and diarrhoea $(5.0 \%)$ occurred in $\geqslant 5 \%$ of patients treated with linsitinib/erlotinib. There were no grade $3 / 4$ TEAEs in $\geqslant 5 \%$ of patients treated with placebo/erlotinib.

Treatment-related AEs were more frequent in patients treated with linsitinib/erlotinib vs placebo/erlotinib (93 vs $87.1 \%$, respectively). The most common treatment-related AEs in patients receiving linsitinib/erlotinib or placebo/erlotinib, respectively, were drug rash/eruption (67.0 vs 58.4\%) and diarrhoea (38.0 vs 28.7\%)
(Table 5). A higher proportion of patients receiving linsitinib/ erlotinib had treatment-related SAEs (15 vs $7.9 \%$ placebo/ erlotinib). The incidence of TEAEs that led to permanent discontinuation of study drug was also higher in patients treated with linsitinib/erlotinib (15\%) than in those treated with placebo/ erlotinib (10.9\%). Of these patients, eight in the linsitinib/erlotinib group and three in the placebo/erlotinib group discontinued study medication due to a treatment-related AE. Similarly, serious TEAEs and serious treatment-related AEs were more common in patients treated with linsitinib/erlotinib. Serious TEAEs were reported for 36 patients (36.0\%) in the linsitinib/erlotinib group and 29 patients $(28.7 \%)$ in the placebo/erlotinib group. Serious treatment-related AEs were reported in 15 patients (15.0\%) receiving linsitinib/erlotinib and eight patients (7.9\%) receiving placebo/erlotinib.

Adverse events of special interest, including renal, hepatic, cardiac, glycaemic, and neurologic AEs, were also investigated. Overall, six patients (6.0\%) receiving linsitinib/erlotinib and eight patients $(7.9 \%)$ receiving placebo/erlotinib experienced renal and urinary disorders. In addition, 11 patients (11.0\%) receiving linsitinib/erlotinib and 10 patients (9.9\%) receiving placebo/ 
Table 4. Pharmacokinetics of erlotinib and linsitinib and pharmacodynamics of insulin-like growth factor-1

Linsitinib/erlotinib

Placebo/erlotinib

\begin{tabular}{|c|c|c|c|c|c|c|c|c|}
\hline & $n$ & Predose & $n$ & 4-h postdose & $n$ & Predose & $n$ & 4-h postdose \\
\hline \multicolumn{9}{|c|}{ Plasma concentration of erlotinib; median, $\mathrm{ng} \mathrm{ml}^{-1}$ (range) } \\
\hline TP1, Day 1 & 67 & $0(0-1380)$ & 31 & $816(0-3700)$ & 64 & $0(0-84)$ & 36 & $883(0-2740)$ \\
\hline TP2, Day 1 & 64 & $974(0-3370)$ & 25 & $1160(0-10300)$ & 68 & $1045(0-3360)$ & 26 & $1565(195-3260)$ \\
\hline TP3, Day 1 & 58 & $930(0-3380)$ & 13 & $1100(0-2660)$ & 65 & $1210(3-3810)$ & 15 & $1100(1.4-5290)$ \\
\hline
\end{tabular}

Plasma concentration of linsitinib; median, $\mathrm{ng} \mathrm{ml}^{-1}$ (range)

\begin{tabular}{|l|l|l|l|l|l|l|l|l|l|l}
\hline TP1, Day 1 & 77 & 0 & 21 & $1030(0-2620)$ & NA & NA & NA & NA \\
TP2, Day 1 & 69 & $455(0-2970)$ & 21 & $898(18-3190)$ & NA & NA \\
TP3, Day 1 & 54 & $639(0-2850)$ & 17 & $1250(42-3210)$ & NA & NA & NA \\
\hline
\end{tabular}

Predose plasma concentrations of insulin-like growth factor-1; median, $\mathrm{ng} \mathrm{ml}^{-1}$ (range)

\begin{tabular}{|l|c|c|r|r}
\hline TP1, Day 1 & 93 & $40(13-122)$ & 93 & 84 \\
TP2, Day 1 & 86 & $61(11-207)$ & 72 & $47(1-132)$ \\
TP3, Day 1 & 65 & $62(20-198)$ & 57 & $45(12-119)$ \\
TP4, Day 1 & 54 & $65(20-147)$ & 49 & $39(17-113)$ \\
TP5, Day 1 & 50 & $63(5-188)$ & $44(14-130)$
\end{tabular}

Abbreviations: $\mathrm{NA}=$ not applicable; $\mathrm{TP}=$ treatment period.

Table 5. All-grade treatment-related AEs $\geqslant 10 \%$ patients in either treatment and grade $3 / 4$ treatment-related AEs

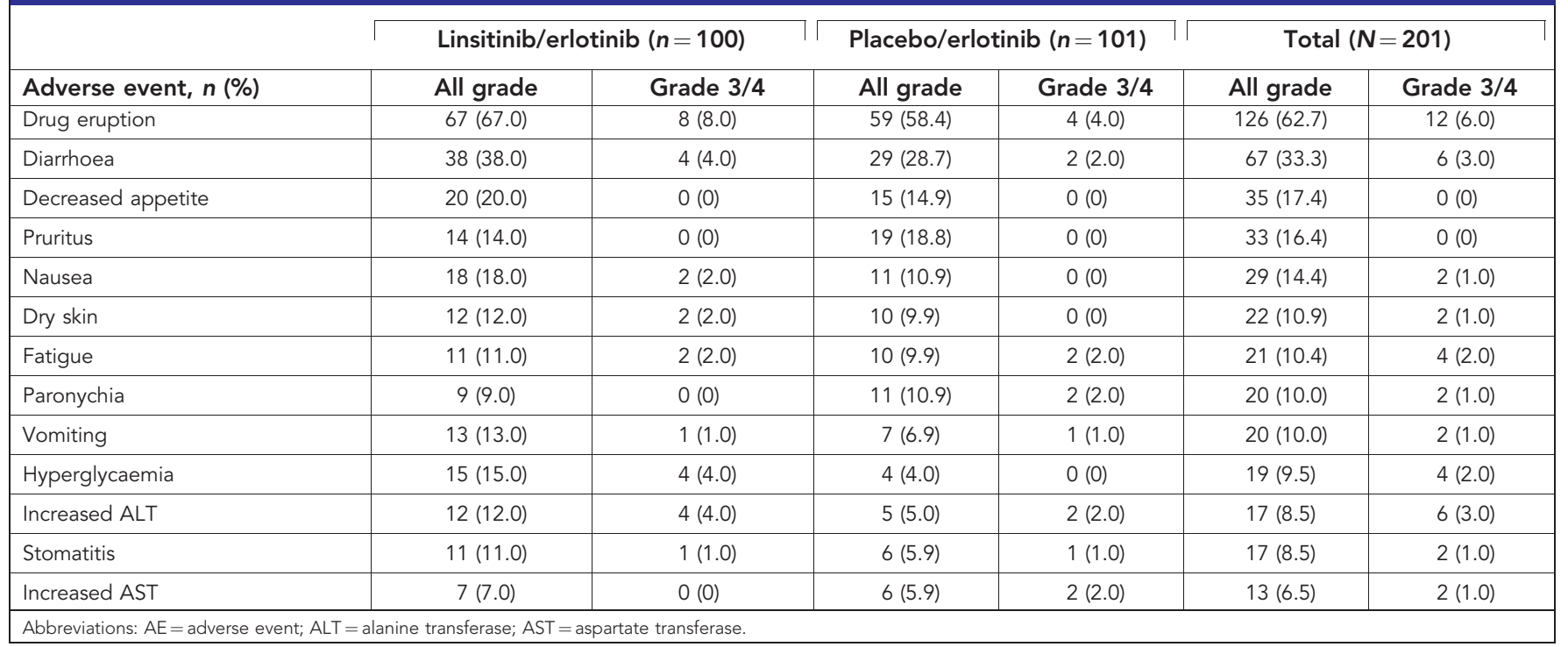

erlotinib experienced increased blood creatinine, and two patients (2.0\%) receiving linsitinib/erlotinib and one patient (1.0\%) receiving placebo/erlotinib experienced hepatobiliary disorders. For both treatment groups, most increases in liver enzymes and liver toxicity markers were low grade. Cardiac disorders (including QTcF interval prolongation) occurred in five patients (5.0\%), each receiving either linsitinib/erlotinib or placebo/erlotinib. Serious cardiac TEAEs occurred in two patients (2\%) receiving placebo/ erlotinib, but not in patients receiving linsitinib/erlotinib. Hyperglycaemia occurred in 19 patients (19.0\%) receiving linsitinib/ erlotinib compared with eight patients $(7.9 \%)$ receiving placebo/ erlotinib; the events were treatment related in 15 patients $(15.0 \%)$ receiving linsitinib/erlotinib (4.0\%, grade $3 / 4$ ) and four patients $(4.0 \%)$ receiving placebo/erlotinib (all grades 1 or 2 ). Nervous system disorders were experienced in 20.0 and $28.7 \%$ of patients receiving linsitinib/erlotinib and placebo/erlotinib, respectively. Overall, five patients had nervous system TEAEs that were considered serious: one patient $(1.0 \%)$ receiving linsitinib/erlotinib and four patients $(4.0 \%)$ receiving placebo/erlotinib.

Twelve deaths occurred during the study, none of which were deemed related to study treatment. In the linsitinib/erlotinib group, one patient died on Day 7 of study treatment due to bacterial pneumonia and six patients died within 30 days of the last administered dose. In patients who received placebo/erlotinib, five patients died within 30 days of last dose. The causes of death in patients receiving linsitinib/erlotinib were respiratory failure or distress $(n=2)$, pneumonia, dyspnoea, pulmonary embolism, abdominal sepsis, and disease progression ( $n=1$ each); and in the patients receiving placebo/erlotinib the causes were disease progression $(n=2)$, dyspnoea, respiratory failure, and neurological decompensation $(n=1$ each).

\section{DISCUSSION}

This randomised Phase II study investigated the effect of linsitinib maintenance therapy in combination with erlotinib compared with erlotinib alone (plus placebo) as maintenance therapy in patients with NSCLC who had not progressed following four cycles of platinum-based chemotherapy. The safety profile in both treatment groups was consistent with expectations for patients with advanced stage NSCLC treated with EGFR inhibitors (Passaro et al, 2014), or linsitinib (Fassnacht et al, 2015; Jones et al, 2015; Puzanov et al, 2015). TEAEs were similar in both treatment groups, although 
SAEs, treatment-related AEs, and serious treatment-related AEs were more frequent among patients randomised to the linsitinib group, as were treatment discontinuations. As expected, due to the mechanisms of action of linsitinib, there was an increased incidence of hyperglycaemia in those receiving linsitinib, although none were considered serious.

Prior clinical studies have demonstrated that maintenance therapy using erlotinib alone in NSCLC is generally well tolerated with a modest prolongation of PFS in patients unselected for the presence of sensitising EGFR mutation (Cappuzzo et al, 2010; Perol et al, 2012). The addition of erlotinib to bevacizumab in maintenance was shown to improve PFS but not OS in a Phase III randomised study (Johnson et al, 2013). Although generally well tolerated, the lack of survival benefit and increased toxicity associated with the addition of erlotinib to bevacizumab maintenance did not lead to a new maintenance standard of care. The rationale for combining linsitinib and erlotinib in maintenance was based on preclinical studies that demonstrated the reciprocal, compensatory signalling between EGFR and IGF-1R pathways on inhibition of either pathway (Buck et al, 2008). Synergistic effects on cancer cell and tumour growth using combinations of linsitinib or other IGF-1R-targeted agents with erlotinib were observed in preclinical studies (Buck et al, 2008). Further studies have also suggested a role for IGF-1R in mediating resistance to EGFRtargeted therapies (Guix et al, 2008; Stewart et al, 2015). Despite strong preclinical evidence and early clinical studies, the results of the present study do not demonstrate any additional benefit from the combination of linsitinib with erlotinib. The results for PFS on both treatment arms are consistent with those obtained for previous studies of maintenance therapy with erlotinib alone (Cappuzzo et al, 2010) or with chemotherapy (Paz-Ares et al, 2013).

Pharmacokinetic data in this study indicated that predose concentrations of erlotinib were similar in both treatment groups, and the results were consistent with the Phase I study indicating a lack of substantial PK drug-drug interaction between erlotinib and linsitinib (Macaulay et al, 2016). Moreover, linsitinib concentrations were similar to those in single-agent studies. Detection of increased plasma IGF-1, a putative pharmacodynamic biomarker of IGF-1R inhibition, in patients who received linsitinib, provides evidence that the dose administered was sufficient to modulate the IGF-1R pathway in these patients (Jones et al, 2015; Puzanov et al, 2015). Therefore, the negative result of this study cannot be attributed to inadequate dosing of either erlotinib or linsitinib. Although there is a theoretical, scientific rationale for dual inhibition of IGF-1R/EGFR (Scagliotti and Novello, 2012), several studies have now reported no improvement in PFS or OS for dual IGF-1R and EGFR inhibition (Ramalingam et al, 2011; Weickhardt et al, 2012; Scagliotti et al, 2015). IGF-1R signalling is inherently complex, involving cross-talk interactions with various feedback mechanisms, and compensatory and redundant signalling pathways in cancer cells (Jin et al, 2013). Therefore, a deeper understanding of the interactions between these pathways is necessary before further development of this combination strategy in NSCLC is warranted.

Biomarker subgroup treatment may be an important caveat in NSCLC maintenance treatment (Gerber and Schiller, 2013; Méry et al, 2015; Zhou et al, 2015). In the context of maintenance erlotinib, in the SATURN trial, the PFS was 44 weeks for a subgroup of patients with tumours bearing activating EGFR mutations, compared with 14 weeks for patients without mutation (Cappuzzo et al, 2010). In the current study, patients with activating EGFR mutations had substantially longer survival in both treatment arms (651 days in the placebo arm and 463 days in the linsitinib arm). There was no significant difference between the arms for this subgroup; however, the survival results observed likely reflect the greater efficacy of erlotinib for tumours with activating EGFR mutation. Therefore, future trials should consider this population separately from the wild-type population when considering sample size and statistical assumptions. The number of patients in this subgroup is unfortunately too low to determine any signal of benefit from the addition of linsitinib, which in theory could mitigate EGFR-TKI resistance due to IGF-1R activation.

Uniform treatment across subgroups, including those defined by biomarker differences, may be an important caveat in the treatment of advanced NSCLC (Méry et al, 2015) and, more specifically, for maintenance treatment (Gerber and Schiller, 2013; Zhou et al, 2015). A difference in PFS was observed in patients with both EGFR wild-type and E-cadherin expression lower than the median, favouring the linsitinib group with median PFS linsitinib vs placebo of 128 vs 82 days $(\mathrm{HR}=0.52,95 \% \mathrm{CI}$, 0.29-0.94). However, due to the small sample sizes and multiple subgroup analyses, these results should be interpreted with caution. Other numeric differences in PFS, which did not reach statistical significance, were observed for patients aged $\geqslant 65$ years in whom PFS was shorter for the linsitinib/erlotinib treatment arm compared with the placebo/erlotinib arm (127 days vs 171 days; $\mathrm{HR}=1.30,95 \% \mathrm{CI}, 0.72-2.34$ ). Additionally, the PFS was longer in the linsitinib/erlotinib treatment arm among patients who were former or current smokers, whereas the PFS was longer in the placebo/erlotinib arm among the never-smokers. This is consistent with the result for patients with activating EGFR mutation, which is likely to occur more frequently in the neversmokers. Similarly, never-smoking and EGFR mutation are known to be associated with adenocarcinoma biology (Gerber and Schiller, 2013; Zhou et al, 2015). In the current study, patients with squamous tumour histology had a median PFS of 127 days on linsitinib vs 113 days on placebo ( $\mathrm{HR}=0.67,95 \% \mathrm{CI}, 0.36-1.24)$. Finally, although numerically a very small subset $(n=16$ for each arm), the PFS for patients with KRAS mutated positive tumours on linsitinib/erlotinib was superior to that for placebo/erlotinib treatment (128 vs 87 days, respectively; $\mathrm{HR}=0.61,95 \% \mathrm{CI}, 0.28-$ 1.36). Looking at all the subset data together, there is a trend for linsitinib to numerically improve the results over erlotinib alone in patients in whom EGFR-TKI are generally less active, such as squamous cell histology, former or current smokers, and EGFR wild-type (with an emphasis on patients with a low E-cadherin level), and in patients with KRAS mutant tumours. At present, these data are an insufficient basis for further clinical evaluation of linsitinib/erlotinib in patients with these characteristics, but are provocative for further preclinical evaluation of relevant tumour types and molecular contexts to explore for this therapeutic approach.

Overall, linsitinib maintenance therapy in combination with erlotinib did not show an improvement of PFS or OS compared with erlotinib alone in molecularly unselected non-progressing NSCLC patients who had completed first-line platinum combination chemotherapy, and does not support further investigation of this combination as maintenance for advanced NSCLC. The negative results cannot be attributed to inadequate drug dosing or excessive toxicity requiring dose adjustments or withdrawal. The results emphasise the need for development of mechanism-based therapies in clinical populations characterised for relevant pharmacodynamic and predictive biomarkers. Identification of candidate biomarkers for response to IGF-1R-targeted therapies is required for further clinical development of this strategy.

\section{ACKNOWLEDGEMENTS}

This research was sponsored by Astellas Pharma, Inc. (Northbrook, IL, USA). Financial support for the development of this manuscript, including editorial assistance under the authors guidance, was provided by Scientific Connexions, Inc. (Lyndhurst, 
NJ, USA), an Ashfield Company, part of UDG Healthcare plc and SuccinctChoice Medical Communications (Chicago, IL, USA) and was funded by the study sponsor.

\section{CONFLICT OF INTEREST}

Tudor-Eliade Ciuleanu has served on an advisory board for Astellas, Amgen, AstraZeneca, Bristol-Myers Squibb, Janssen, Eli Lilly, Merck, Merck Sharp and Dohme, Pfizer, Roche, and Boehringer Ingelheim. JHK declares grant funding from AstraZeneca, Boehringer Ingelheim, Bristol-Myers Squibb, Eli Lilly and Company, and Roche. KP has served in an advisory role for Astellas and Roche. JC, SP, JMV, and DW were employed with Astellas at the time of the study. SA, JM, MT, and FB have no conflicts to disclose.

\section{REFERENCES}

Belfiore A, Frasca F, Pandini G, Sciacca L, Vigneri R (2009) Insulin receptor isoforms and insulin receptor/insulin-like growth factor receptor hybrids in physiology and disease. Endocr Rev 30: 586-623.

Buck E, Gokhale PC, Koujak S, Brown E, Eyzaguirre A, Tao N, Rosenfeld-Franklin M, Lerner L, Chiu MI, Wild R, Epstein D, Pachter JA, Miglarese MR (2010) Compensatory insulin receptor (IR) activation on inhibition of insulin-like growth factor-1 receptor (IGF-1R): rationale for cotargeting IGF-1R and IR in cancer. Mol Cancer Ther 9: 2652-2664.

Buck E, Eyzaguirre A, Rosenfeld-Franklin M, Thomson S, Mulvihill M, Barr S, Brown E, O’Connor M, Yao Y, Pachter J, Miglarese M, Epstein D, Iwata KK, Haley JD, Gibson NW, Ji QS (2008) Feedback mechanisms promote cooperativity for small molecule inhibitors of epidermal and insulin-like growth factor receptors. Cancer Res 68: 8322-8332.

Cappuzzo F, Ciuleanu T, Stelmakh L, Cicenas S, Szczésna A, Juhász E, Esteban E, Molinier O, Brugger W, Melezínek I, Klingelschmitt G, Klughammer B, Giaccone G. SATURN investigators (2010) Erlotinib as maintenance treatment in advanced non-small cell lung cancer: a multicentre, randomized, placebo-controlled phase 3 study. Lancet Oncol 11: $521-529$.

Chung C (2016) Tyrosine kinase inhibitors for epidermal growth factor receptor gene mutations-positive non-small cell lung cancers: an update for recent advances in therapeutics. J Oncol Pharm Pract 22: 461-476.

Ciuleanu T, Brodowicz T, Zielinski C, Kim JH, Krzakowski M, Laack E, Wu YL, Bover I, Begbie S, Tzekova V, Cucevic B, Pereira JR, Yang SH, Madhavan J, Sugarman KP, Peterson P, John WJ, Krejcy K, Belani CP (2009) Maintenance pemetrexed plus best supportive care versus placebo plus best supportive care for non-small-cell lung cancer: a randomized, double blind, phase 3 study. Lancet 374: 1432-1440.

Eisenhauer EA, Therasse P, Bogaerts J, Schwartz LH, Sargent D, Ford R, Dancey J, Arbuck S, Gwyther S, Mooney M, Rubinstein L, Shankar L, Dodd L, Kaplan R, Lacombe D, Verweij J (2009) New response evaluation criteria in solid tumours: revised RECIST guideline (version 1.1). Eur J Cancer 45: 228-247.

Fassnacht M, Berruti A, Baudin E, Demeure MJ, Gilbert J, Haak H, Kroiss M, Quinn DI, Hesseltine E, Ronchi CL, Terzolo M, Choueiri TK, Poondru S, Fleege T, Rorig R, Chen J, Stephens AW, Worden F, Hammer GD (2015) Linsitinib (OSI-906) versus placebo for patients with locally advanced or metastatic adrenocortical carcinoma: a double-blind, randomized, phase 3 study. Lancet Oncol 16: 426-435.

Fidler MJ, Shersher DD, Borgia JA (2012) Targeting the insulin-like growth factor receptor pathway in lung cancer: problems and pitfalls. Ther $A d v$ Med Oncol 4: 51-60.

Gao J, Chang YS, Jallal B, Viner J (2012) Targeting the insulin-like growth factor axis for the development of novel therapeutics in oncology. Cancer Res 72: 3-12.

Gerber DE, Schiller JH (2013) Maintenance chemotherapy for advanced nonsmall cell lung cancer: new life for an old idea. J Clin Oncol 31: 1009-1020.

Genestreti G, Di Battista M, Cavallo G, Bartolotti M, Brandes AA (2015) Maintenance therapy in non-small cell lung cancer. Expert Rev Anticancer Ther 15: 839-846.
Guix M, Faber AC, Wang SE, Olivares MG, Song Y, Qu S, Rinehart C, Seidel B, Yee D, Arteaga CL, Engelman JA (2008) Acquired resistance to EGFR tyrosine kinase inhibitors in cancer cells is mediated by loss of IGF-binding proteins. J Clin Invest 118: 2609-2619.

Janssen JA, Varewijck AJ (2014) IGF-IR targeted therapy: past, present and future. Frontiers Endocrinol 5: 224.

Ji QS, Mulvihill MJ, Rosenfeld-Franklin M, Cooke A, Feng L, Mak G, O'Connor M, Yao Y, Pirritt C, Buck E, Eyzaguirre A, Arnold LD, Gibson NW, Pachter JA (2007) A novel, potent, and selective insulin-like growth factor-I receptor kinase inhibitor blocks insulin-like growth factor-I receptor signaling in vitro and inhibits insulin-like growth factor-I receptor dependent tumor growth in vivo. Mol Cancer Ther 6 : 2158-2167.

Jin M, Buck E, Mulvihill MJ (2013) Modulation of insulin-like growth factor-1 receptor and its signaling network for the treatment of cancer: current status and future perspectives. Oncol Rev 7(1): e3.

Johnson BE, Kabbinavar F, Fehrenbacher L, Hainsworth J, Kasubhai S, Kressel B, Lin C-Y, Marsland T, Patel T, Polikoff J, Rubin M, White L, Yang JC-H, Bowden C, Miller V (2013) ATLAS: randomized, double-blind, placebo-controlled, phase IIIB trial comparing bevacizumab therapy with or without erlotinib, after completion of chemotherapy, with bevacizumab for first-line treatment of advanced non-small-cell lung cancer. J Clin Oncol 31: 3926-3934.

Jones R, Kim E, Nava-Parada P, Alam S, Johnson FM, Stephens AW, Simantov R, Poondru S, Gedrich R, Lippman SM, Kaye SB, Carden CP (2015) Phase I study of intermittent oral dosing of the insulin-like growth factor-1 and insulin receptors inhibitor OSI-906 in patients with advanced solid tumors. Clin Cancer Res 21: 693-700.

Kim JS, Kim ES, Liu D, Lee J, Solis L, Behrens C, Lippman SM, Hong WK, Wistuba, Lee H-Y (2014) Prognostic implications of tumoral expression of insulin like growth factors 1 and 2 in patients with non-small-cell lung cancer. Clin Lung Cancer 15: 213-221.

King H, Aleksic T, Haluska P, Macaulay VM (2014) Can we unlock the potential of IGF-1R inhibition in cancer therapy? Cancer Treat Rev 40: 1096-1105.

Lu S, Yu Y, Chen Z, Ye X, Li Z, Niu X (2015) Maintenance therapy improves survival outcomes in patients with advanced non-small cell lung cancer: a meta-analysis of 14 studies. Lung 193: 805-814.

Macaulay VM, Middleton MR, Eckhardt SG, Rudin CM, Juergens RA, Gedrich R, Gogov S, McCarthy S, Poondru S, Stephens AW, Gadgeel SM (2016) Phase I dose-escalation study of linsitinib (OSI-906) and erlotinib in patients with advanced solid tumors. Clin Cancer Res 22: 2897-2907.

Manegold C (2014) Treatment algorithm in 2014 for advanced non-small cell lung cancer: Therapy selection by tumour histology and molecular biology. Adv Med Sci 59: 308-313.

McKinley ET, Bugaj JE, Zhao P, Guleryuz S, Mantis C, Gokhale PC, Wild R, Manning HC (2011) ${ }^{18}$ FDG-PET predicts pharmacodynamics response to OSI-906, a dual IGF-1R/IR inhibitor, in preclinical mouse models of lung cancer. Clin Cancer Res 17: 3332-3340.

Melosky B. Review of EGFR TKIs in Metastatic NSCLC, Including Ongoing Trials (2014) Front Oncol 4: 244.

Méry B, Guy JB, Swalduz A, Vallard A, Guibert C, Almokhles H, Mrad MB, Rivoirard R, Falk AT, Fournel P, Magné N (2015) The evolving locally-advanced non-small cell lung cancer landscape: building on past evidence and experience. Crit Rev Oncol Hematol 96: 319-327.

Mulvihill MJ, Cooke A, Rosenfeld-Franklin M, Buck E, Foreman K, Landfair D, O'Connor M, Pirritt C, Sun Y, Yao Y, Arnold LD, Gibson NW, Ji QS (2009) Discovery of OSI-906: a selective and orally efficacious dual inhibitor of the IGF-1 receptor and insulin receptor. Future Med Chem 1: 1153-1171.

Paez JG, Janne PA, Lee JC, Tracy S, Greulich H, Gabriel S, Herman P, Kaye FJ, Lindeman N, Boggon TJ, Naoki K, Sasaki H, Fujii Y, Eck MJ, Sellers WR, Johnson BE, Meyerson M (2004) EGFR mutations in lung cancer: correlation with clinical response to gefitinib therapy. Science 304: $1497-1500$

Passaro A, Di Maio M, Del Signore E, Gori B, de Marinis F (2014) Management of nonhematologic toxicities associated with different EGFR-TKIs in advanced NSCLC: a comparison analysis. Clin Lung Cancer 15: 307-312.

Patel JD, Socinski MA, Garon EB, Reynolds CH, Spigel DR, Olsen MR, Hermann RC, Jotte RM, Beck T, Richards DA, Guba SC, Liu J, Frimodt-Moller B, John WJ, Obasaju CK, Pennella EJ, Bonomi P, 
Govindan R (2013) PointBreak: a randomized phase III study of premetrexed plus carboplatin and bevacizumab followed by maintenance bevacizumab versus paclitaxel plus carboplatin and bevacizumab followed by maintenance bevacizumab in patients with stage IIIB or IV nonsquamous non-small-cell lung cancer. J Clin Oncol 31: 4349-4357.

Paz-Ares LG, de Marinis F, Dediu M, Thomas M, Pujol JL, Bidoli P, Molinier O, Sahoo TP, Laack E, Reck M, Corral J, Melemed S, John W, Chouaki N, Zimmermann AH, Visseren-Grul C, Gridelli C (2013) PARAMOUNT: Final overall survival results of the phase III study of maintenance pemetrexed versus placebo immediately after induction treatment with pemetrexed plus cisplatin for advanced nonsquamous non-small-cell lung cancer. J Clin Oncol 31: 2895-2902.

Perol M, Chouaid C, Perol D, Barlési F, Gervais R, Westeel V, Crequit J, Léna H, Vergnenègre A, Zalcman G, Monnet I, Le Caer H, Fournel P, Falchero L, Poudenx M, Vaylet F, Ségura-Ferlay C, DevouassouxShisheboran M, Taron M, Milleron B (2012) Randomized, phase III study of gemcitabine or erlotinib maintenance therapy versus observation, with predefined second-line treatment, after cisplatin-gemcitabine induction chemotherapy in advanced non-small cell lung cancer. J Clin Oncol 30: 3516-3524.

Pillai RN, Ramalingam SS (2013) Inhibition of insulin-like growth factor receptor: end of a targeted therapy? Transl Lung Cancer Res 2: 14-22.

Pollack M (2012) The insulin and insulin-like growth factor receptor family in neoplasia: an update. Nat Rev Cancer 12: 159-169.

Puzanov I, Lindsay CR, Goff L, Sosman J, Gilbert J, Berlin J, Poondru S, Simantov R, Gedrich R, Stephens A, Chan E, Evans TRJ (2015) Phase I, dose-escalation study of continuous oral dosing of OSI-906, a dual inhibitor of insulin-like growth factor receptor 1 and insulin receptor tyrosine kinases, in patients with advanced solid tumors. Clin Cancer Res 21: 701-711.

Ramalingam SS, Spigel DR, Chen D, Steins MB, Engelman JA, Schneider CP, Novello S, Eberhardt WE, Crino L, Habben K, Liu L, Jänne PA, Brownstein CM, Reck M (2011) Randomized phase II study of erlotinib in combination with placebo or R1507, a monoclonal antibody to insulin-like growth factor-1 receptor, for advanced-stage non-small-cell lung cancer. $J$ Clin Oncol 29: 4574-4580.

Rosell R, Moran T, Queralt C, Porta R, Cardenal F, Camps C, Majem M, Lopez-Vivanco G, Isla D, Provencio M, Insa A, Massuti B, Gonzalez-Larriba JL, Paz-Ares L, Bover I, Garcia-Campelo R, Moreno MA, Catot S, Rolfo C, Reguart N, Palmero R, Sánchez JM, Bastus R, Mayo C, Bertran-Alamillo J, Molina MA, Sanchez JJ, Taron M. Spanish Lung Cancer Group (2009) Screening for epidermal growth factor receptor mutations in lung cancer. $N$ Engl J Med 361: 958-967.

Rothschild SI (2015) Targeted therapies in non-small cell lung cancer-beyond EGFR and ALK. Cancers 7: 930-949.

Sandler A, Herbst R (2006) Combining targeted agents: blocking the epidermal growth factor and vascular endothelial growth factor pathways. Clin Cancer Res 12: 4421s-4425s.

Scagliotti GV, Novello S (2012) The role of insulin-like growth factor signaling pathway in non-small cell lung cancer and other solid tumors. Cancer Treatment Rev 38: 292-302.
Scagliotti GV, Bondarenko I, Blackhall F (2015) Randomized, phase III trial of figitumumab in combination with erlotinib versus erlotinib alone in patients with nonadenocarcinoma nonsmall-cell lung cancer. Ann Oncol 26: 497-504.

Sharma SV, Lee DY, Li B, Quinlan MP, Takahashi F, Maheswaran S, McDermott U, Azizian N, Zou L, Fischbach MA, Wong KK, Brandstetter K, Wittner B, Ramaswamy S, Classon M, Settleman J (2010) A chromatin-mediated reversible drug-tolerant state in cancer cell subpopulations. Cell 141: 69-80.

Stewart EL, Tan SZ, Liu G, Tsao M (2015) Known and putative mechanisms of resistance to EGFR targeted therapies in NSCLC patients with EGFR mutations-a review. Transl Lung Cancer Res 4: 67-81.

Torre LA, Bray F, Siegel RL, Ferlay J, Lortet-Tieulent J, Jemal A (2015) Global cancer statistics, 2012. CA Cancer J Clin 65: 87-108.

Ulanet DB, Ludwig DL, Kahn CR, Hanahan D (2010) Insulin receptor functionally enhances multistage tumor progression and conveys intrinsic resistance to IGF-1R targeted therapy. Proc Natl Acad Sci USA 107: 10791-10798.

Weickhardt A, Doebele R, Oton A, Lettieri J, Maxson D, Reynolds M, Brown A, Jackson MK, Dy G, Adjei A, Fetterly G, Lu X, Franklin W, Varella-Garcia M, Hirsch FR, Wynes MW, Youssoufian H, Adjei A, Camidge DR (2012) A phase I/II study of erlotinib in combination with the anti-insulin-like growth factor-1 receptor monoclonal antibody IMC-A12 (cixutumumab) in patients with advanced non-small cell lung cancer. J Thorac Oncol 7: 419-426.

Zhang C, Huang C, Wang J, Wang X, Li K (2015) Maintenance or consolidation therapy for non-small cell lung cancer: a meta-analysis involving 5841 subjects. Clin Lung Cancer 16: e15-e23.

Zhang L, Ma S, Song X, Han B, Cheng Y, Huang C, Yang S, Liu X, Liu Y, Lu S, Wang J, Zhang S, Zhou C, Zhang X, Hayashi N, Wang M. INFORM investigators (2012) Gefitinib versus placebo as maintenance therapy in patients with locally advanced or metastatic non-small-cell lung cancer (INFOR; C-TONG 0804): a multicentre, double-blind randomised phase 3 trial. Lancet Oncol 13: 466-475.

Zhao H, Desai V, Wang J, Epstein DM, Miglarese M, Buck E (2012) Epithelial-mesenchymal transition predicts sensitivity to the dual IGF-1R/ IR inhibitor OSI-906 in hepatocellular carcinoma cell lines. Mol Cancer Ther 11: 503-513.

Zhou F, Jiang T, Ma W, Gao G, Chen X, Zhou C (2015) The impact of clinical characteristics on outcomes from maintenance therapy in non-small lung cancer: a systematic review with meat-analysis. Lung Cancer 89: 203-211.

Zinn RL, Gardner EE, Marchionni L, Murphy SC, Dobromilskaya I, Hann CL, Rudin CM (2013) ERK phosphorylation is predictive of resistance to IGF-1R inhibition in small cell lung cancer. Mol Cancer Ther 12: 1131-1139.

This work is published under the standard license to publish agreement. After 12 months the work will become freely available and the license terms will switch to a Creative Commons AttributionNonCommercial-Share Alike 4.0 Unported License. 